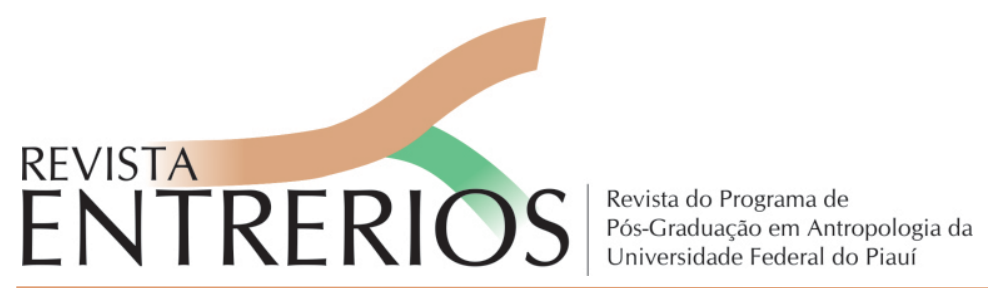

\title{
GONZÁLEZ VARELA, Sergio Armando. Capoeira, mobility, and tourism: preserving an Afro-Brazilian tradition in a globalized world. Lanham: Lexington Books, 2019.
}

\author{
Luiz Gustavo Mendel Souza \\ Doutor em Antropologia \\ Professor na Universidade Federal Fluminense, Brasil \\ luizgmendel@gmail.com
}

Mestre Pastinha, o codificador da Capoeira Angola na década de 1940, estabeleceu como fundamento desta arte marcial a autoridade dos mestres, reservando para estes líderes o papel de mentores da vida de seus discípulos para além das rodas. Porém, os pilares da capoeira não passariam ilesos pelos efeitos da globalização e pela expansão da cultura afro-brasileira dentro e fora do território nacional.

Mas a circulação dos mestres e grupos de Capoeira Angola atravessa e é atravessada por questões que impossibilitam a fixação das lideranças nos países estrangeiros, tais como: idioma, empregos estáveis, choque cultural, aceitação familiar, dentre outros. Desta forma, os ensinamentos passam a ser transmitidos sazonalmente pelos mestres itinerantes, inviabilizando a construção do relacionamento mestre-aluno proposto por Pastinha.

É neste complexo quadro que surgem os seguintes questionamentos: como abordar a Capoeira Angola no século XXI? Como trabalhar com a noção de origem, tradição e fundamento numa arte marcial que se encontra espalhada pelos quatro cantos do mundo? Quais os efeitos da globalização para a noção de luta e resistência presente na Capoeira Angola? Quais as apropriações que os capoeiristas dão para o título de Patrimônio da Humanidade e para a lógica de mercado ao consumir a Capoeira Angola?

Para responder estas questões Sergio González Varela traz mais uma obra abordando a Capoeira Angola como um universo de possibilidades analíticas em: Capoeira, mobility, and tourism: preserving an Afro-Brazilian tradition in a globalized world (2019). A metodologia da Antropologia da Mobilidade foi aplicada nesta pesquisa através do acompanhamento dos mestres e seus alunos, mostrando as falas e os posicionamentos dos interlocutores diante da organização de grupos de Capoeira Angola espalhados por cinco países: México, Inglaterra, Espanha, Suécia e Brasil. O livro explora como a dinâmica dos circuitos realizados por mestres e alunos reestruturam e reorganizam a tradição, a ancestralidade, o fundamento cosmológico, diante das influências locais e globais. 
Este livro é o desdobramento de outra pesquisa realizada pelo autor: Power in Practice: the paradigmatic anthropology of Afro-Brazilian Capoeira (2017) ${ }^{1}$. Ambas as obras foram frutos de um trabalho de campo de dois anos na cidade de Salvador na Bahia, além dos treinamentos e workshops que o antropólogo participou na Suécia e Londres, soma-se sua relação de longa data com o grupo de Capoeira Angola da cidade do México. Na tese de 2017, Varela debruçou-se sobre a busca de uma legitimidade discursiva do trabalho missionário dos capoeiristas através da linhagem de seus líderes. Em Capoeira, mobility, and tourism, o pesquisador reforça este argumento acrescentando que a fundação de um grupo em uma determinada cidade estrangeira é uma forma de garantir conexões políticas, sociais, culturais e econômicas, além de e expandir a autoridade e prestígio de um determinado mestre ou grupo.

Para a organização desta obra, o livro é dividido em seis capítulos tendo como fio condutor as noções de tradição, ancestralidade e cultura afro-brasileira. Estes três elementos são categorias em disputa pela comunidade angoleira, surgindo através da ênfase na legitimidade discursiva dos mestres itinerantes analisados pelo autor.

O primeiro capítulo intitula-se: History, Mythology, and the Local Imaginaries of Capoeira², nele compreendemos a importância das narrativas históricas e míticas para a criação de uma esfera própria da Capoeira Angola, fazendo com que esta seja entendida como um mundo em $\mathrm{si}^{3}$. A intenção de Varela é focar nos sentidos de "brasilidade" e "africanidade" que os praticantes atribuem à Capoeira Angola e a Regional. Mas o fator crucial que permeia todas as páginas deste capítulo é a fascinação que envolve os intelectuais e capoeiristas com a origem africana da capoeira. O N'golo ou "dança da zebra", prática ritual angolana que se tornou o elo que autentica e legitima a arte marcial brasileira e a mãe África. Outros componentes que preenchem o imaginário social da capoeira é o entendimento desta como uma arte marcial praticada nos quilombos como forma de resistência contra a escravidão, tendo como elemento chave a apropriação de heróis históricos como Zumbi dos Palmares, além da existência de personagens míticos e mágicos como Besouro Mangangá. Para o antropólogo, todas estas categorias afetam diretamente a capoeira, agenciando concretamente as práticas dos lutadores através da construção identitária dos capoeiristas.

O capítulo 2 chama-se: Global Expansion: Making Sense of Mobility ${ }^{4}$, aqui, a intenção do autor é relacionar os itinerários globais realizados pelos mestres e estudantes avançados com os sentidos atribuídos por estes à missão de expandir a Capoeira Angola pelo mundo. Nas páginas deste capítulo, Varela descreve metodológica e analiticamente as implicações de uma Antropologia da Mobilidade, baseado em Mimi Sheller, John Urry, Jillian Rickly, Kevin Hannam e Mary Mostafanezhad. Esta escolha metodológica visa tratar a complexidade da abordagem etnográfica para a circulação de capoeiristas sujeitos às intempéries do cotidiano em meio aos seus deslocamentos. Aqui a mobilidade se torna um objeto de análise, assim como Tim Ingold, Varela compreende esta experiência como "[...] the nomadic trajectory as an open-ended project in a world in constant motion where planning and making, as activities, are almost synonymous" (VARELA, 2019: 46) ${ }^{5}$. Para exemplificar esta problemática, Varela dialoga com a história e os projetos de três mestres e a fundação de seus grupos em Londres: Mestre Carlão do Grupo Kabula, Mestre Fantasma do grupo Filhos de Angola (um mestre não-brasileiro) e Mestre Joãozinho da Figueira do grupo Mar Azul.

1 VARELA, Sergio Gonzáles. Power in Practice: the paradigmatic anthropology of Afro-Brazilian Capoeira. New York: Berghahn, 2017.166 pp.

2 Mitologia, História e Imaginários Locais da Capoeira (VARELA, 2019, tradução nossa).

3 O autor propôs este mesmo recurso analítico em Power in Pratice (2017), compreendendo a Capoeira Angola como um mundo em si, ou seja, entendendo as categorias circunscritas da comunidade angoleira como distintas das duas outras modalidades: Luta Regional Baiana e capoeira Contemporânea.

4 Expansão Global: fazendo sentido de mobilidade (VARELA, 2019, tradução nossa).

5 " [...] trajetória nômade como um projeto aberto em um mundo em constante movimento onde o planejamento e a realização, como atividades, são quase sinônimos." (VARELA, 2019:46, tradução nossa). 
O paradigma da Mobilidade é a chave para a compreensão do estilo de vida dos mestres e praticantes de Capoeira Angola que se encontra em um fluxo constante entre seu país de origem e a fundação do seu grupo no exterior. As experiências itinerantes e o acaso do cotidiano contribuem para a reformulação da identidade do capoeirista, nas palavras de Varela: "Mobility is a political statement of the cosmopolitan citizen, and it is reconfiguring the meaning of belonging to an Afro-Brazilian tradition" (idem: 62$)^{6}$.

O capítulo 3 intitula-se: The Mestre-Student Relationship in the Age of Tourism ${ }^{7}$ a questão principal aqui é como os ensinamentos sazonais, proporcionados pelo fluxo contínuo dos mestres entre os países, vão minar o fundamento da Capoeira Angola elaborada por mestre Pastinha. Para isto, a virtualidade do turismo é pensada através da "invenção da cultura" de Roy Wagner, Varela propõe a aproximação do termo turismo ao conceito de cultura para compreender como o processo inventivo do turismo tem afetado a relação "tradicional" de conhecimento entre professores e alunos.

O argumento defendido nestas páginas é como uma nova relação mestre-aluno é reformulada em meio a uma contradição. Pois, para o codificador da Capoeira Angola, o mestre não se limitaria a um professor de artes marciais, mas um guia para a vida do aluno, um homem que incorporaria a tradição alicerçada pelas linhagens dos grupos de capoeira. Porém, ao realizar muitas viagens, os mestres criaram novas relações locais dentro da capoeira, gerando, concomitantemente, novos laços mestre-alunos. Nas palavras do autor: "Traveling fractured forever the traditional relationship between mestres and students" (VARELA, 2019:72). Este novo modelo de relacionamento mestre-aluno é esquematizado em três momentos: 1) maravilhado - quando os alunos se deparam com a aura de poder e autoridade dos mestres renomados em seus países; 2) expectativas - referente aos imaginários que os alunos criam diante das narrativas dos mestres e suas origens e linhagens; 3) desapontamento - no que diz respeito ao desgaste da relação entre os alunos e os mestres missionários, onde os mestres não podem ser líderes presentes no cotidiano dos alunos e os alunos não incorporam o fundamento da capoeira.

O capítulo 4 intitula-se: Religious Foundations ${ }^{9}$, nele encontramos uma busca pelo status ontológico da capoeira. Onde, na máxima de Mestre Pastinha: “capoeira é manha, é malícia, é tudo que a boca come", permite-nos a compreensão de que o jogo da capoeira angola não se encerra dentro da roda, mas expande-se para a vida cotidiana. O elemento chave desta conexãoé a figura do mestre.

O mestre assume o papel de guardião da tradição da Capoeira Angola. Aqui, se o carisma weberiano é a chave da manutenção do poder político dos mestres, os elementos mágicos da mandinga e malandragem são acionados como elementos de reconhecimento de poder mágico, espiritual e religioso dos mestres. Para Varela, o fundamento religioso da Capoeira Angola é fruto da interação de elementos do Candomblé e da Umbanda (no sul do Brasil) que se manifestam da seguinte maneira: no respeito à autoridade do mestre, nas músicas e nos ritmos, nos Orixás, nos rituais de proteção e na admiração aos ancestrais africanos. A força vital do axé e os mistérios da mandinga contornam os lutadores poderosos através dos seus desempenhos dentro do jogo da capoeira. Por outro lado, há também a presença de uma ancestralidade manifesta através dos heróis míticos entoados na roda de capoeira.

O quinto capítulo Worshipping the Ancestors ${ }^{10,}$ nele vemos como a capoeira é entendida como a transformação do discurso da ancestralidade em ação. As várias temporalidades que remetem uma África mítica e uma "brasilidade" envolta pela resistência negra à escravidão atravessam os corpos dos jogadores dentro da roda de capoeira.

\footnotetext{
6"A mobilidade é uma afirmação política do cidadão cosmopolita e está reconfigurando o sentido de pertencer a uma tradição afro-brasileira." (idem:62, tradução nossa).

7 Relacionamento mestre-aluno na era do turismo (idem).

8 "As viagens fraturaram para sempre o relacionamento tradicional entre mestres e alunos." (VARELA, 2019: 72, tradução nossa).

9 Fundamento Religioso (VARELA, 2019, tradução nossa).

10 Cultuando os Ancestrais (VARELA, 2019:119, tradução nossa).
}

EntreRios - Revista do PPGANT -UFPI -Teresina ・Vol. 2, n. 2 (2019) 
A legitimidade das linhagens dos grupos confunde-se com as histórias dos mestres, que assim como Mestre Pastinha e Mestre Bimba, aprenderam a arte com africanos autênticos. Sergio González Varela demonstra o quanto a ancestralidade manifesta-se na Capoeira Angola através das histórias contadas, músicas cantadas, das pinturas nos murais e nas estampas das camisas e nas performances dos praticantes. No momento da realização dos jogos na roda, os corpos dos mestres são a ponte que liga o passado ao presente, sendo estes também os mantenedores do futuro da Capoeira Angola.

A problemática da mobilidade aparece aqui nos revelando o quanto as questões socioeconômicas atrapalham os mestres brasileiros a se estabelecerem em países de terceiro mundo como o México, concomitantemente, a sazonalidade missionária dos líderes brasileiros desestabiliza as relações mestre-aluno defendida por Mestre Pastinha. De acordo com Varela, alguns grupos de Capoeira Angola começam a se estruturar reivindicando autonomia e, desta forma, afastando-se das linhagens brasileiras. Esta autonomia manifesta-se através dos cultos ancestrais permeados pela santeria afro-cubana, neo-xamanismo, danças culturais neo-Asceta e pela adoção de personagens históricos no corpo mítico da capoeira como Emiliano Zapata. Nas palavras do autor: "For Mexicans, both Zumbi and Zapata are symbols of freedom and justice and pertain to the same mythological pantheon of capoeira spirits" (VARELA, 2019:119).

O capítulo 6 é o "Capoeira as Intangible Cultural Heritage" ${ }^{12}$, nele temos a apresentação do processo histórico de patrimonialização da capoeira como bem imaterial brasileiro pelo IPHAN (Instituto do Patrimônio Histórico e Artístico Nacional) em 2008 e como Patrimônio da Humanidade pela UNESCO (Organização das Nações Unidas para a Educação, a Ciência e a Cultura) em 2014. O cerne deste capítulo é um exercício metodológico sobre as apropriações e atribuições que os mestres capoeiristas podem utilizar do título de Patrimônio para realizarem seus projetos comerciais e identitários. Para isto, Sergio González Varela nos convida para uma incômoda reflexão: até onde a categoria de Patrimônio da Humanidade pode ser apropriada pelos seus agentes?

O debate é pautado na análise de dois casos distintos e assimétricos: a organização do evento internacional "Red Bull Paranauê" e a ocupação cultural das proximidades do Porto Maravilha na cidade do Rio de Janeiro pelo Grupo de Capoeira Kabula com o projeto "Memórias do Cais do Valongo". De um lado, vemos a articulação de mestres de renome em parceria com a Prefeitura de Salvador, Empresa Salvador Turismo e fábrica de bebida energética multinacional na organização da Red Bull Paranauê. Aqui, as articulações dos apoiadores do megaevento são colocadas em contraste com os posicionamentos de personagens notáveis no mundo da capoeira como Mestre Cobra Mansa que denuncia a apropriação mercadológica e colonial da manifestação da resistência negra na história do Brasil. De outro, vemos a articulação de Mestre Carlão e seu Grupo Kabula na organização do "Projeto Roda dos Saberes do Cais do Valongo", propondo uma ocupação cultural da região próxima ao Porto Maravilha na cidade do Rio de Janeiro pela Capoeira Angola. Ambas as situações são utilizadas como casos exemplares para questionarmos as potencialidades e os limites da apropriação da capoeira como Patrimônio Imaterial pelos seus agentes e o quanto estas reverberam socialmente.

Em suma, Capoeira, mobility, and tourism: preserving an Afro-Brazilian tradition in a globalized world traz para a discussão temas que estão em voga na atualidade como migração, turismo, globalização e patrimônio. A Capoeira Angola é o objeto e o fio condutor de uma análise antropológica que pode ser aplicada nas mais diversas áreas das Ciências Humanas, contribuindo com as proposições e ferramentas da Antropologia da Mobilidade.

11 "Para os mexicanos, Zumbi e Zapata são símbolos de liberdade e justiça e pertencem ao mesmo panteão mitológico dos espíritos de capoeira" (VARELA, 2019: 119, tradução nossa).

12 A Capoeira como Patrimônio Cultural de Natureza Imaterial (idem, tradução nossa). 
Celso de Brito

Daniel Granada

Monica Aceti

(Orgs.)

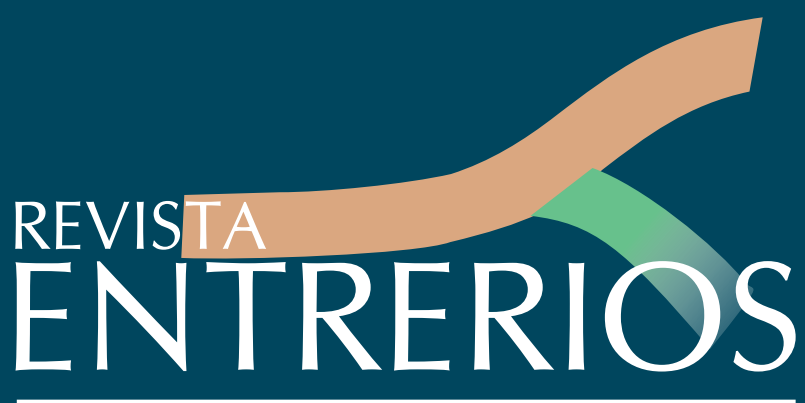

Revista do Programa de

Pos-Graduação em Antropologia da

Universidade Federal do Piaú 